\title{
OPEN Abnormal promoter DNA hypermethylation of the integrin, nidogen, and dystroglycan genes in breast cancer
}

\author{
Vladimir V. Strelnikov ${ }^{1 凶}$, Ekaterina B. Kuznetsova ${ }^{1,3}$, Alexander S. Tanas ${ }^{1}$, \\ Viktoria V. Rudenkoㅇ, Alexey I. Kalinkin ${ }^{1}$, Elena V. Poddubskaya ${ }^{4,5}$, Tatiana V. Kekeeva ${ }^{1}$, \\ Galina G. Chesnokova ${ }^{1}$, Ivan D. Trotsenko ${ }^{6}$, Sergey S. Larin ${ }^{7,8}$, Sergey I. Kutsev ${ }^{1}$, \\ Dmitry V. Zaletaev ${ }^{1,3}$, Marina V. Nemtsova ${ }^{1,3}$ \& Olga A. Simonova ${ }^{2}$
}

Cell transmembrane receptors and extracellular matrix components play a pivotal role in regulating cell activity and providing for the concerted integration of cells in the tissue structures. We have assessed DNA methylation in the promoter regions of eight integrin genes, two nidogen genes, and the dystroglycan gene in normal breast tissues and breast carcinomas (BC). The protein products of these genes interact with the basement membrane proteins LAMA1, LAMA2, and LAMB1; abnormal hypermethylation of the $\angle A M A 1, \angle A M A 2$, and $\angle A M B 1$ promoters in $B C$ has been described in our previous publications. In the present study, the frequencies of abnormal promoter hypermethylation in BC were $13 \%$ for ITGA1, 31\% for ITGA4, 4\% for ITGA7, 39\% for ITGA9, 38\% for NID1, and $41 \%$ for NID2. ITGA2, ITGA3, ITGA6, ITGB1, and DAG1 promoters were nonmethylated in normal and BC samples. ITGA4, ITGA9, and NID1 promoter hypermethylation was associated with the HER2 positive tumors, and promoter hypermethylation of ITGA1, ITGA9, NID1 and NID2 was associated with a genome-wide CpG island hypermethylated BC subtype. Given that ITGA4 is not expressed in normal breast, one might suggest that its abnormal promoter hypermethylation in cancer is nonfunctional and is thus merely a passenger epimutation. Yet, this assumption is not supported by our finding that it is not associated with a hypermethylated BC subtype. ITGA4 acquires expression in a subset of breast carcinomas, and methylation of its promoter may be preventive against expression in some tumors. Strong association of abnormal ITGA4 hypermethylation with the HER2 positive tumors $(p=0.0025)$ suggests that simultaneous presence of both HER 2 and integrin $\alpha 4$ receptors is not beneficial for tumor cells. This may imply HER2 and integrin $\alpha 4$ signaling pathways interactions that are yet to be discovered.

Cell transmembrane receptors and extracellular matrix components play a pivotal role in regulating cell functioning and ensure concerted cell integration in the tissue structure. Malignant transformation is associated with dramatic alterations in cell signaling. Such alterations affect both cancer cell behavior and components of the tumor microenvironment. In turn, microenvironmental components may both promote and suppress the pathological process ${ }^{1}$

Concerted integration of morphogenetic signals and proper cell adhesion and migration are essential for preserving and maintaining the tissue structure by cells. Regulatory mechanisms include ligand-receptor

\footnotetext{
${ }^{1}$ Epigenetics Laboratory, Research Centre for Medical Genetics, Moskvorechie St 1, 115522 Moscow, Russia. ${ }^{2}$ Molecular Genetic Diagnostics Laboratory 2, Research Centre for Medical Genetics, Moskvorechie St 1, 115522 Moscow, Russia. ${ }^{3}$ Medical Genetics Laboratory, I.M. Sechenov First Moscow State Medical University (Sechenov University), Trubetskaya St 8-2, 119991 Moscow, Russia. ${ }^{4}$ Clinic of Personalized Medicine, I.M. Sechenov First Moscow State Medical University (Sechenov University), Trubetskaya St 8-2, 119991 Moscow, Russia. ${ }^{5}$ VitaMed LLC, Seslavinskaya St 10, 121309 Moscow, Russia. ${ }^{6}$ Institute of Medicine, Peoples' Friendship University of Russia (RUDN University), Miklukho-Maklaya St 6, 117198 Moscow, Russia. ${ }^{7}$ Molecular Immunology Laboratory, Federal Scientific Clinical Centre of Pediatric Hematology Oncology Immunology Named After Dmitry Rogachev, Samory Mashela St 1, 117997 Moscow, Russia. ${ }^{8}$ Gene Therapy Laboratory, Institute of Gene Biology, Vavilova St 34/5, 119334 Moscow, Russia. ${ }^{\boxplus}$ email: vstrel@list.ru
} 

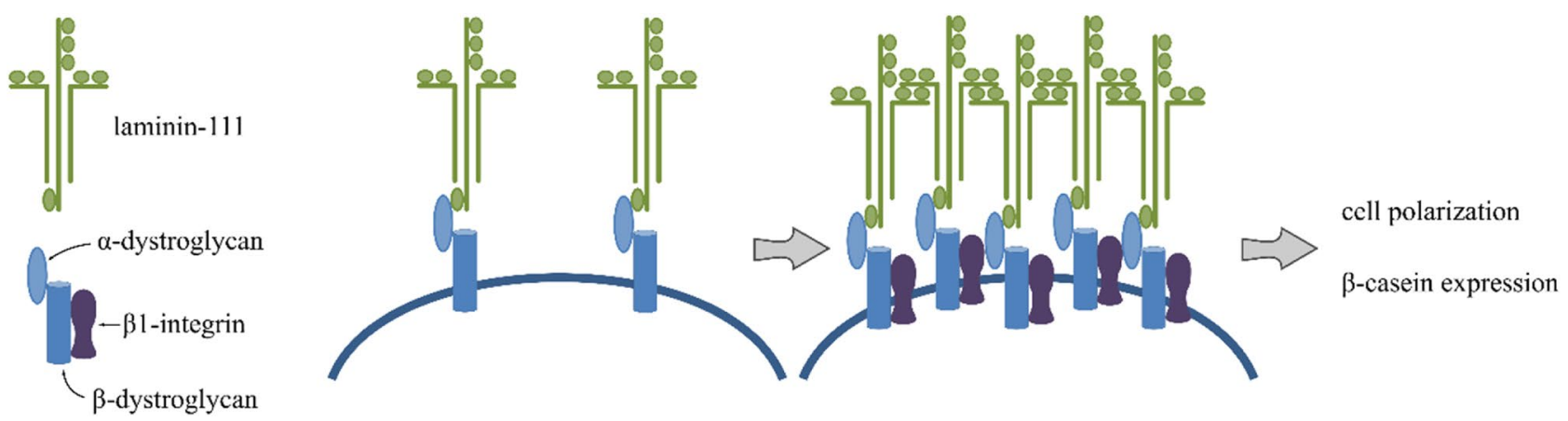

Figure 1. Laminins, integrins, and dystroglycan interactions are considered prerequisite for polarization and normal functioning of the mammary cell.

interactions of cells with surrounding components. The interactions that involve laminins, integrins, and dystroglycan (Fig. 1) are critical for the function of breast epithelial cells ${ }^{2}$.

The integrin family is one of the important classes of cell transmembrane receptors. Structurally, integrins are heterodimers of $\alpha$ and $\beta$ subunits, which are noncovalently bound with each other. A total of $18 \alpha$ and $8 \beta$ subunits are known today. Their pairwise interactions produce at least $24 \alpha \beta$ receptor combinations. As their important functions, integrins mediate bidirectional signaling and contribute to cell adhesion by forming hemidesmosomes and focal contacts. Integrins trigger various regulatory cascades by converting external signals to internal ones. Integrins are capable of affecting various cell processes, such as growth, differentiation, adhesion, migration, and apoptosis ${ }^{3}$.

Given that multiple functions are mediated by integrins, one can assume that integrins are involved in cell malignant transformation, invasion, and metastasis. Ample data have accumulated to date to characterize the role that integrins play in morphogenesis and function of the breast epithelium, and changes in integrin expression have been observed in $\mathrm{BC}^{4}$.

We have previously examined three laminin subunit genes (LAMA1, LAMA2, and LAMB1), the promoter regions of which undergo abnormal methylation in breast cancer (BC) at frequencies higher than $16 \%{ }^{5}$. In the present study, we drew attention to the genes encoding proteins that can interact with laminin molecules that incorporate the products of the $L A M A 1, L A M A 2, L A M B 1$ genes. The group of interacting molecules includes integrin subunits ITGA1, ITGA2, ITGA3, ITGA6, ITGA7, ITGA9, ITGB1 genes, a dystroglycan (DAG1) gene 6,7 $^{6,}$ and nidogens NID1 and NID2 genes ${ }^{8,9}$. ITGA4, also included in this study, settles somewhat aside from these genes: in some publications, the possibility of interaction of its product with laminin-111 was described; however, it is currently believed that interaction with laminins is not its main function ${ }^{10}$. Yet, data has accumulated indicating its involvement in a variety of cancers including $\mathrm{BC}^{11-14}$, which was the reason for its inclusion.

To date, most detailed information in terms of tumorigenesis is available for two integrin subunits selected for this study, ITGA9 and ITGA4. ITGA9 is a component of integrin $\alpha 9 \beta 1$, which is capable of interacting with many molecules, including thrombospondin 1, ADAM12/ADAM15, the nerve growth factor, VCAM1, laminin, fibronectin, tenascin C, osteopontin, VEGF-C, and VEGF-D ${ }^{15}$. ITGA9 expression is vital, and ITGA9 knockout mice die on day 6-12 of embryo development. Integrin $\alpha 9 \beta 1$ is involved in regulating cell adhesion, migration, differentiation, and proliferation. The role that integrin $\alpha 9$ plays in carcinogenesis has been the focus of many studies. Upregulation of integrin a9 expression has been observed in medulloblastoma ${ }^{16}$, astrocytoma, and glioblastoma ${ }^{17}$. On the other hand, a NotI microarray study of genetic and epigenetic ITGA9 alterations has shown that its deletions and methylation occur at a high $(>30 \%)$ frequency in renal cell, lung, breast, ovarian, cervical, and rectal cancers. In breast tumors, ITGA9 expression was downregulated or totally absent in $44 \%$ of cases and intact or upregulated in $45 \%$ of cases. The frequency of ITGA9 promoter methylation was $90 \%$ in the former group. Treatment with the demethylating agent 5-aza-dC restored integrin $\alpha 9$ expression in ITGA9negative cells of the MCF7 line ${ }^{18}$. A study of cervical carcinoma has detected ITGA9 deletions in $41 \%$ of cases and abnormal promoter methylation in $24 \%$ of cases $^{19}$. It is important to note that ITGA9 is in the so-called AP20 region of chromosome 3p21.3. The region is a hot spot of homozygous deletions in renal cell, lung, and breast carcinomas and is involved in malignant transformation of various epithelial cells ${ }^{20}$. Apart from deletions, extended fragments with an altered methylation status and modified chromatin have been observed in this region in rectal tumors ${ }^{21}$. Interesting observations have been made in a large pedigree with Lynch syndrome. Its members suffered from various cancers, including endometrial, rectal, hepatic, gastric, breast, and brain cancers; leukemia; etc. A molecular testing revealed a large 400-kb deletion involving LRRFIP2, GOLGA4, and C3orf35/APRG1. The deletion produced a fusion gene combining MLH1 exons 1-11 with ITGA9 exons 17-28. It is thought that the 3 '-terminal transmembrane and cytoplasmic domains of MLH1/ITGA9 interact with other cell proteins to exert their complex effect on the biology of the affected cell. Mismatch repair is abolished in tumor cells that are devoid of $M L H 1$ and carry at least one $M L H 1 / I T G A 9$ fusion copy, potentially leading to global genome instability ${ }^{20}$.

The ITGA4 gene product is a component of two integrins, $\alpha 4 \beta 1$ and $\alpha 4 \beta 7$, and has been studied in detail to date. Yet, there is still no consensus as to the role integrin a 4 plays in tumorigenesis. Some studies demonstrate that integrin $\alpha 4$ acts as a tumor suppressor, while others show that its expression correlate with the extent of cell malignant transformation and metastasis ${ }^{22}$. Abnormal ITGA4 methylation has been observed in colorectal 


\begin{tabular}{|c|c|c|c|c|c|c|c|c|}
\hline \multirow[b]{2}{*}{ Gene } & \multirow[b]{2}{*}{ Methylated in breast cancer } & \multirow[b]{2}{*}{ Methylated in tissues adjacent to tumor } & \multirow{2}{*}{$\begin{array}{l}\text { Methylated in normal autopsy breast } \\
\text { tissues }\end{array}$} & \multicolumn{5}{|c|}{$\begin{array}{l}\text { Presence }(+) \text { or absence }(-) \text { of methylation in } \\
\text { breast cancer cell lines }\end{array}$} \\
\hline & & & & ZR751 & MCF7 & T47D & BT474 & HS578T \\
\hline ITGAI & $13 \%(19 / 146)$ & $1 \%(1 / 146)$ & $0 \%(0 / 6)$ & - & - & - & - & - \\
\hline ITGA2 & $0 \%(0 / 156)$ & $0 \%(0 / 156)$ & $0 \%(0 / 6)$ & - & - & - & - & - \\
\hline ITGA3 & $0 \%(0 / 156)$ & $0 \%(0 / 156)$ & $0 \%(0 / 6)$ & - & - & - & - & - \\
\hline ITGA4 & $31 \%(48 / 156)$ & $3 \%(4 / 156)$ & $0 \%(0 / 6)$ & + & + & + & + & - \\
\hline ITGA6 & $0 \%(0 / 156)$ & $0 \%(0 / 156)$ & $0 \%(0 / 6)$ & - & - & - & - & - \\
\hline ITGA7 & $4 \%(6 / 156)$ & $1 \%(1 / 156)$ & $0 \%(0 / 6)$ & - & - & - & + & - \\
\hline ITGA9 & $39 \%(61 / 156)$ & $2 \%(3 / 156)$ & $0 \%(0 / 6)$ & + & + & + & + & - \\
\hline ITGB1 & $0 \%(0 / 156)$ & $0 \%(0 / 156)$ & $0 \%(0 / 6)$ & - & - & - & - & - \\
\hline$D A G 1$ & $0 \%(0 / 156)$ & $0 \%(0 / 156)$ & $0 \%(0 / 6)$ & - & - & - & - & - \\
\hline NID1 & $38 \%(59 / 154)$ & $2 \%(3 / 156)$ & $0 \%(0 / 6)$ & + & + & + & - & + \\
\hline NID2 & $41 \%(63 / 153)$ & $2 \%(3 / 156)$ & $0 \%(0 / 6)$ & - & + & + & + & - \\
\hline
\end{tabular}

Table 1. Methylation status of integrin, nidogen, and dystroglycan CpG islands assessed by MSRE-PCR in breast tissues and cell lines.

cancer $^{23,24}$, cholangiocarcinoma ${ }^{13}$, gastric and bladder tumors ${ }^{11}$. Integrin $\alpha 4 \beta 1$ may promote melanoma cell adhesion to the vascular endothelium. Higher-level ITGA4 expression may suppress the detachment and invasion of cancer cells and, on the other hand, may promote their dissemination by increasing their interaction with surface ligands of endothelial cells ${ }^{25}$.

Like integrins, dystroglycan also acts as a cell surface receptor. Dystroglycan consists of two subunits, $\alpha$ and $\beta$, which are synthesized as a propeptide from one mRNA; the propeptide is then cleaved proteolytically into two noncovalently associated subunits. Dystroglycan interacts with various extracellular matrix components, such as laminins, perlican, and agrin. In muscle cells, dystroglycan ensures physical contacts between the cytoskeleton and the basement membrane. Dystroglycan is also expressed in other cells and plays a role in epithelial morphogenesis, cell adhesion, and signal transduction ${ }^{2}$.

Studies of dystroglycan in breast tissue have shown its importance for maintaining the cell polarity, tissue architectonics, and $\beta$-casein secretion ${ }^{26}$. Diminished function of $\alpha$-dystroglycan has been associated with a more aggressive tumor phenotype in $\mathrm{BC}$ cell lines ${ }^{27}$.

Nidogens are another family of essential components of the extracellular matrix. The family includes only two members, nidogens 1 and 2. Structurally, nidogens are 150-kDa sulfated glycorpoteins that consist of three globular domains. Nidogen surface presents binding sites for extracellular matrix proteins, such as laminins, collagens, and integrins. Nidogen-1, which is also known as entactin-1, interacts with integrins, perlican, and fibulin and can form a triple complex with collagen IV and laminin 111. The latter interaction underlies the formation of all basement membranes. Mesenchymal and myoepithelial cells express nidogen-1 in breast tissues. Nidogen- 1 is thought to modulate the signals transmitted by laminin 111, in particular, to regulate $\beta$-casein expression ${ }^{28}$. Nidogen-2 interacts with the same matrix molecules as nidogen-1 with the exception of fibulin. In addition, nidogen-2 binds with endostatin and tropoelastin. Inactivation of nidogen-2 has led to a higher frequency of melanoma metastasis to the lung in experiments with mice ${ }^{29}$.

Nidogens play a role in epithelial morphogenesis by regulating cell adhesion and maintaining the basement membrane integrity and indirectly affect signal transduction ${ }^{30}$. Although nidogens are involved in these processes, little is still known today on their role in tumorigenesis. Negrini et al.$^{31}$ have observed that the promoter regions of NID1 and NID2 are abnormally methylated in 67 and 29\% of rectal cancer cases, respectively. Methylation of the two regions has additionally been detected in more than $90 \%$ of cases in gastric cancer. Abnormal methylation of the promoter regions in NID1 and NID2 is accompanied by lack of their expression in the MCF7, MDA-MB-231, and BT-20 BC cell lines. A demethylating agent has been shown to restore their expression in MDA-MB-231 cells ${ }^{31}$. It has recently been reported that endothelial cell-derived nidogen-1 inhibits migration of SK-BR-3 breast cancer cells ${ }^{32}$.

Methylation of the promoter region is one of the mechanisms that regulate gene expression. In this work, we have assessed methylation status of the promoter regions of the integrin, dystroglycan, and nidogen genes, and have evaluated the association of their abnormal hypermethylation with expression and epigenetic subtypes of breast cancer.

\section{Results}

DNA methylation at ITGA1, ITGA2, ITGA3, ITGA4, ITGA6, ITGA7, ITGA9, ITGB1, NID1, NID2, and DAG1 gene promoters in normal and malignant breast tissues and cell lines. Data for the integrin, nidogen, and dystroglycan genes 5'-cytosine-phosphate-guanine-3' (CpG) islands assessed by methylation-sensitive restriction enzyme digestion PCR (MSRE-PCR) are summarized in Table 1. Based on the results of MSRE-PCR, the genes were classified into two categories: genes with CpG islands nonmethylated in normal breast tissues but prone to abnormal hypermethylation in BC (ITGA1, ITGA4, ITGA7, ITGA9, NID1, and NID2), and genes with CpG islands found to be nonmethylated in all breast tissues, no matter normal or cancerous (ITGA2, ITGA3, ITGA6, ITGB1, and DAG1). 


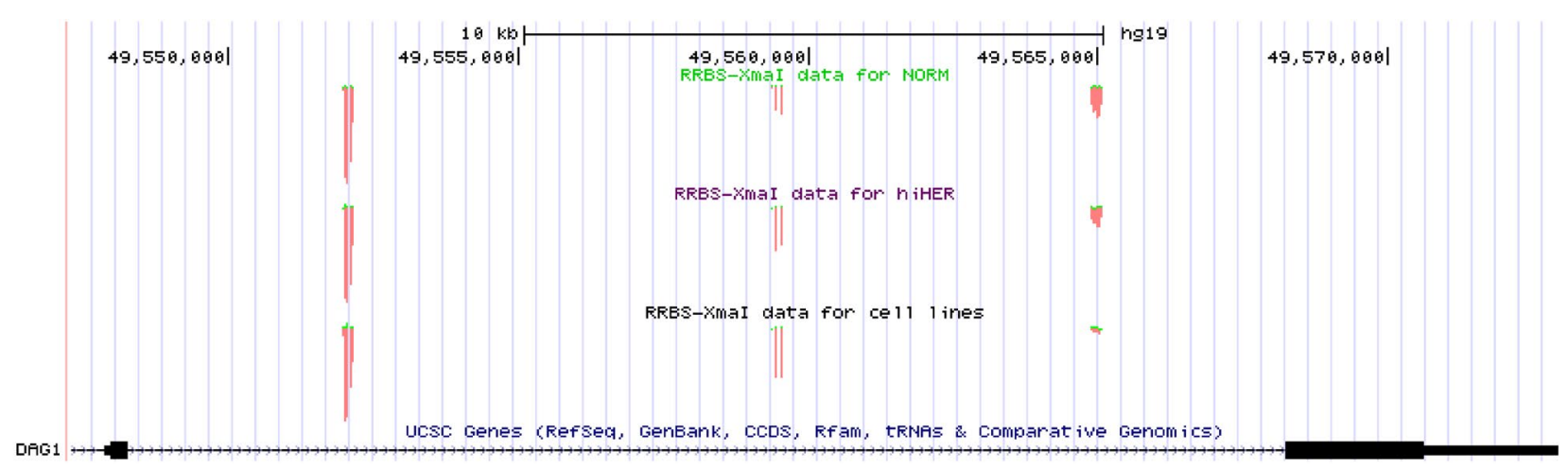

Figure 2. DNA methylation within a DAG1 gene intron separating the two coding DAG1 exons, assessed by XmaI-RRBS. The results are presented as a screenshot of our UCSC Genome Browser custom track that summarizes CpG methylation levels for all the samples that have been studied: normal breast tissues, upper track; BC tissues, middle track, BC cell lines, lower track. Prevalence of methylated CpGs in all three groups of samples is obvious from the prevalence of a fraction marked red. Nonmethylated fraction is marked green, and it is negligible. The two coding exons of the DAG1 gene are schematically shown at the figure bottom.

Breast cancer cell lines were analyzed alongside with the clinical samples in order to validate the results of our MSRE-PCR assays, and to provide reference information that can be reevaluated by other researchers. By now, the ENCODE project ${ }^{33}$ collection of data on DNA methylation obtained by reduced representation bisulfite sequencing (RRBS) contains information regarding two of the cell lines assessed in our study, MCF7 and T47D. For these, our MSRE-PCR results demonstrated in Table 1 recapitulate the ENCODE RRBS data for the ITGA1, ITGA4, ITGA9, NID1 and NID2 promoters approving the validity of our approach. ITGA7 gene promoter is not covered by the ENCODE RRBS.

Nonmethylated status of the promoter CpG islands of the ITGA1, ITGA2, ITGA3, ITGA4, ITGA6, ITGA9, ITGB1, NID1, NID2 and DAG1 genes determined by MSRE-PCR in normal breast tissues in our study is in line with the ENCODE RRBS results for the normal breast tissue sample (BC_Breast_02-03015; breast, donor 02-03015, age 21, Caucasian, DNA extract). For ITGA7 gene promoter, RRBS information is not available in the ENCODE.

Nonmethylated status of the promoter CpG islands of the ITGA3, ITGA4, ITGA6, ITGA9, ITGB1, NID1, NID2 and DAG1 genes in normal breast tissues is also supported by XmaI-RRBS previously performed by us on the same six autopsy samples ${ }^{34}$. ITGA1, ITGA2 and ITGA7 gene promoters are not covered with XmaI-RRBS data.

DNA methylated status of the regions assessed by MSRE-PCR was confirmed by a validating method of bisulfite sequencing by Sanger. Bisulfite Sanger sequencing was performed for the promoter of ITGA7, which evaded from ENCODE RRBS and XmaI-RRBS, to confirm its nonmethylated status in normal and tumor samples; and for one of the promoters (NID2) that demonstrated differential methylation by MSRE-PCR, to validate nonmethylated status in normal samples and abnormal methylation in cancer. ITGA7 and NID2 promoter regions were bisulfite sequenced in one normal sample and four tumor samples and the results confirmed MSRE-PCR findings in all cases.

DNA methylation within a DAG1 gene intron. Alongside with the gene promoters' methylation information, our XmaI-RRBS results ${ }^{34}$ provide information on the methylation status of CpG-rich fragments of an intron separating the two coding exons of $D A G 1$, one of the genes of interest in this study. The results presented on Fig. 2 demonstrate overwhelming prevalence of methylated alleles in BC samples and BC cell lines, as well as in normal breast tissues, indicating no or negligible evolutionary advantage of this area hypomethylation for breast cancer cells. Of note, this region is not covered in the available ENCODE project RRBS dataset ${ }^{33}$.

Associations of hypermethylation of the ITGA1, ITGA4, ITGA9, NID1, and NID2 gene promoters and characteristics of breast tumors. Further analysis was focused on the ITGA1, ITGA4, ITGA9, NID1, and NID2 genes in which we have identified CpGs nonmethylated in normal breast tissues but prone to abnormal hypermethylation in BC, with hypermethylation found in no less than $5 \%$ of samples from our collection.

A multiple correspondence analysis was carried out in order to suggest clinical and genetic associations between the methylation status of ITGA1, ITGA4, ITGA9, NID1, and NID2 and clinical/morphological characteristics of the tumors, including the disease stage, tumor grade, tumor type, as well as estrogen receptor, progesterone receptor, and HER2 expression assessed by immunohistochemistry (IHC). By multiple correspondence analysis, potential association with abnormal methylation of ITGA1, ITGA4, ITGA9, NID1, and NID2 was observed only for the HER2 expression level (Fig. 3).

Representations of BC samples with hypermethylated promoters in groups with different levels of HER2 expression are shown on Fig. 4. The association between the methylated gene status and high HER2 expression was confirmed by the $\chi^{2}$ and Fisher's exact tests for ITGA4, ITGA9, and NID1 (Table 2). 
2D Plot of Column Coordinates; Dimension: $1 \times 2$

Input Table (Rows x Columns): 14 x 14 (Burt Table)

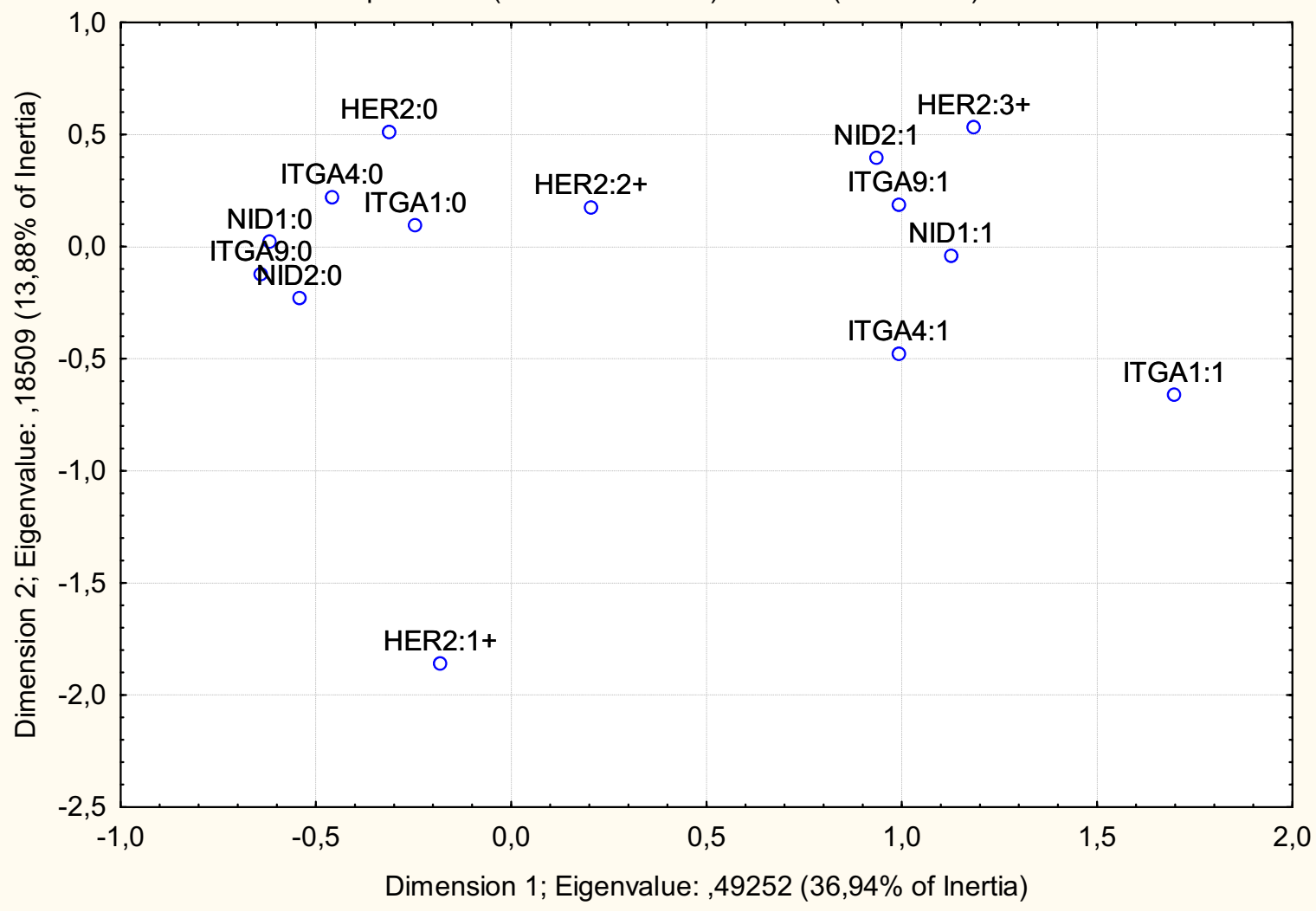

Figure 3. High HER2 expression (IHC score 3+) is associated with the methylated status of the ITGA1, ITGA4, ITGA9, NID1, and NID2 genes in breast cancer samples by the results of multiple correspondence analysis. The nonmethylated gene status is designated as " 0 " at the gene symbol; methylated as " 1 " at the gene symbol. Multiple correspondence analysis allows investigating the structure of objects and variables that characterize them, initially included in the multi-input table, where objects (samples) are located in rows, and grouping variables $(\mathrm{N})$ in columns, which are object coordinates in the $\mathrm{N}$-dimensional space. The goal of the multiple correspondence analysis is to represent the contents of the table transformed into a table of relative frequencies of grouping variables as a projection on a 2-dimensional space. Dimension 1 explains $36.94 \%$ inertia, that is, for the data in question, the values of the relative frequencies that are reconstructed from one dimension contribute to the $\chi^{2}$ statistics (and, therefore, inertia) for $36.94 \%$ of the original. Both dimensions explain $50.82 \%$ of the $\chi^{2}$ value. Groups of samples that have signs of grouping variables located in the same fields are considered the closest. For example, on this plot, patients with a methylated status of the ITGA9 and NID2 genes and a high level of HER2 expression in breast cancer samples form a pronounced common cluster. A somewhat less pronounced commonality is demonstrated by the samples with methylated status of the ITGA1, ITGA4, and NID1 genes.

We have also identified positive association of the CpG island hypermethylated status of the ITGA1, ITGA9, NID1 and NID2 genes in tumors with their attribution to the hypermethylated epigenomic BC subtype determined for a subset of samples from the same collection by genome-wide bisulfite sequencing of the CpG islands by XmaI-RRBS. Interestingly, we found no such association for the ITGA4 gene (Table 3).

For the ITGA4, ITGA9, NID1 and NID2 genes for which XmaI-RRBS data are available, we have calculated the relative fractions of methylated and nonmethylated alleles in tumor samples, in respect to HER2 expression in tumors. The results are shown on Fig. 5.

\section{Discussion}

We have previously examined DNA methylation at the CpG islands of all laminin subunit genes and have shown that the promoter regions of $L A M A 1, L A M A 2$, and $L A M B 1$ are affected by abnormal methylation in $\mathrm{BC}$ with the frequencies of $29 \%, 26 \%$ and $16 \%$ respectively ${ }^{5}$. The present study focuses on the genes for eleven proteins that are capable of interacting with the LAMA1, LAMA2, and LAMB1 products.

We have studied the methylation status of eight integrin gene promoters in normal and BC cells, and observed abnormal hypermethylation in BC for ITGA1, ITGA4, ITGA7, and ITGA9. 


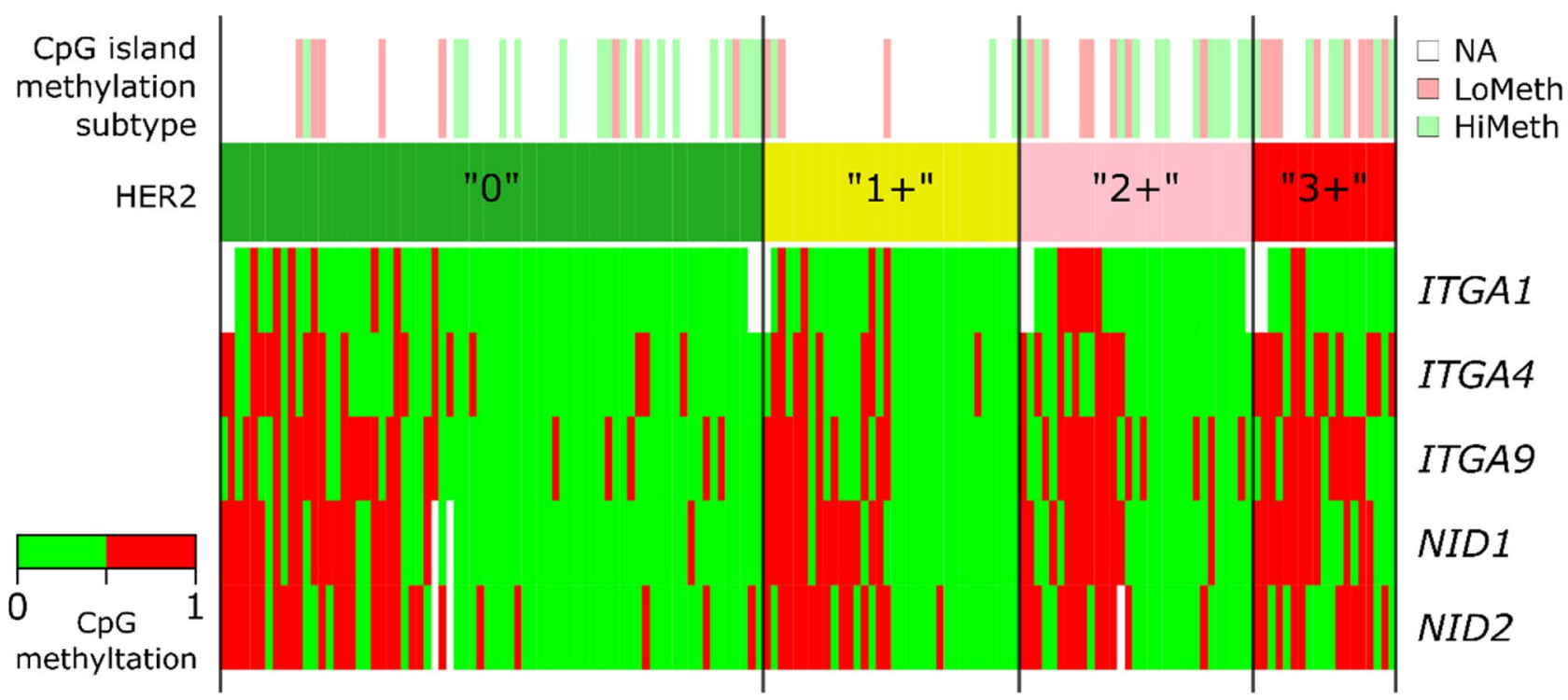

Figure 4. Promoter CpG methylation heatplot for the ITGA1, ITGA4, ITGA9, NID1, and NID2 genes in the groups of breast cancer samples with different levels of HER2 expression designated as " 0 ", " $1+$ ", " $2+$ " and " $3+$ " according to the IHC scores. LoMeth and HiMeth (CpG island methylation subtype track) are the moderately methylated and hypermethylated BC subtypes previously assigned to a subset of samples from the same tissue collection on the basis of a genome-wide DNA methylotyping ${ }^{34}$. NA, genome-wide DNA methylotyping data were not generated for the sample. The heatmap demonstrates methylated (red) or nonmethylated (green) statuses of the assessed promoter CpG dinucleotides. Blank fields stand for DNA methylation MSRE-PCR data missing for technical reasons.

\begin{tabular}{|c|c|c|c|c|c|}
\hline \multirow[b]{2}{*}{ Gene } & \multicolumn{4}{|c|}{ HER2 expression, IHC score } & \multirow[b]{2}{*}{ Significant differences } \\
\hline & “0” & "1+" & “2+" & “3+" & \\
\hline ITGA1 & $10 \%(7 / 68)$ & $12 \%(4 / 33)$ & $21 \%(6 / 28)$ & $12 \%(2 / 17)$ & None \\
\hline \multirow[t]{2}{*}{ ITGA4 } & $26 \%(19 / 72)$ & $26 \%(9 / 34)$ & $26 \%(8 / 31)$ & $63 \%(12 / 19)$ & “0” vs “ $3+$ +", $p=0.0054$ \\
\hline & \multicolumn{3}{|l|}{$26 \%(36 / 137)$} & $63 \%(12 / 19)$ & “ $0,1+, 2+$ " vs “" $3+, p=0.0025$ \\
\hline \multirow[t]{2}{*}{ ITGA9 } & $32 \%(23 / 72)$ & $32 \%(11 / 34)$ & $48 \%(15 / 31)$ & $63 \%(12 / 19)$ & None \\
\hline & \multicolumn{2}{|l|}{$32 \%(34 / 106)$} & $48 \%(15 / 31)$ & $63 \%(12 / 19)$ & “0, 1+” vs “ $3+$ ", $p=0.0199$ \\
\hline NID1 & $30 \%(21 / 70)$ & $41 \%(14 / 34)$ & $39 \%(12 / 31)$ & $63 \%(12 / 19)$ & “0” vs “ $3+$ ", $p=0.017$ \\
\hline NID2 & $37 \%(26 / 70)$ & $41 \%(14 / 34)$ & $40 \%(12 / 30)$ & $58 \%(11 / 19)$ & None \\
\hline
\end{tabular}

Table 2. Abnormal hypermethylation of $\mathrm{CpG}$ dinucleotides in the promoter regions of integrin and nidogen genes in breast cancer samples in relation to HER2 status.

\begin{tabular}{|l|l|l|l|}
\hline \multirow{2}{*}{ Gene } & \multicolumn{2}{|l|}{ Genome-wide tumor methylotype } & Significant differences \\
\cline { 2 - 4 } & Moderately methylated at CpG islands & Hypermethylated at CpG islands & Fisher's exact test \\
\hline ITGA1 & $0 \%(0 / 33)$ & $22 \%(5 / 23)$ & $p=0.01$ \\
\hline ITGA4 & $26 \%(10 / 38)$ & $42 \%(11 / 26)$ & None \\
\hline ITGA9 & $26 \%(10 / 38)$ & $62 \%(16 / 26)$ & $p=0.01$ \\
\hline NID1 & $16 \%(6 / 38)$ & $65 \%(17 / 26)$ & $p=0.0002$ \\
\hline NID2 & $19 \%(7 / 37)$ & $69 \%(18 / 26)$ & $p=0.0002$ \\
\hline
\end{tabular}

Table 3. Abnormal hypermethylation of $\mathrm{CpG}$ dinucleotides in the promoter regions of integrin and nidogen genes in breast cancer samples in relation to genome-wide tumor methylotype. 

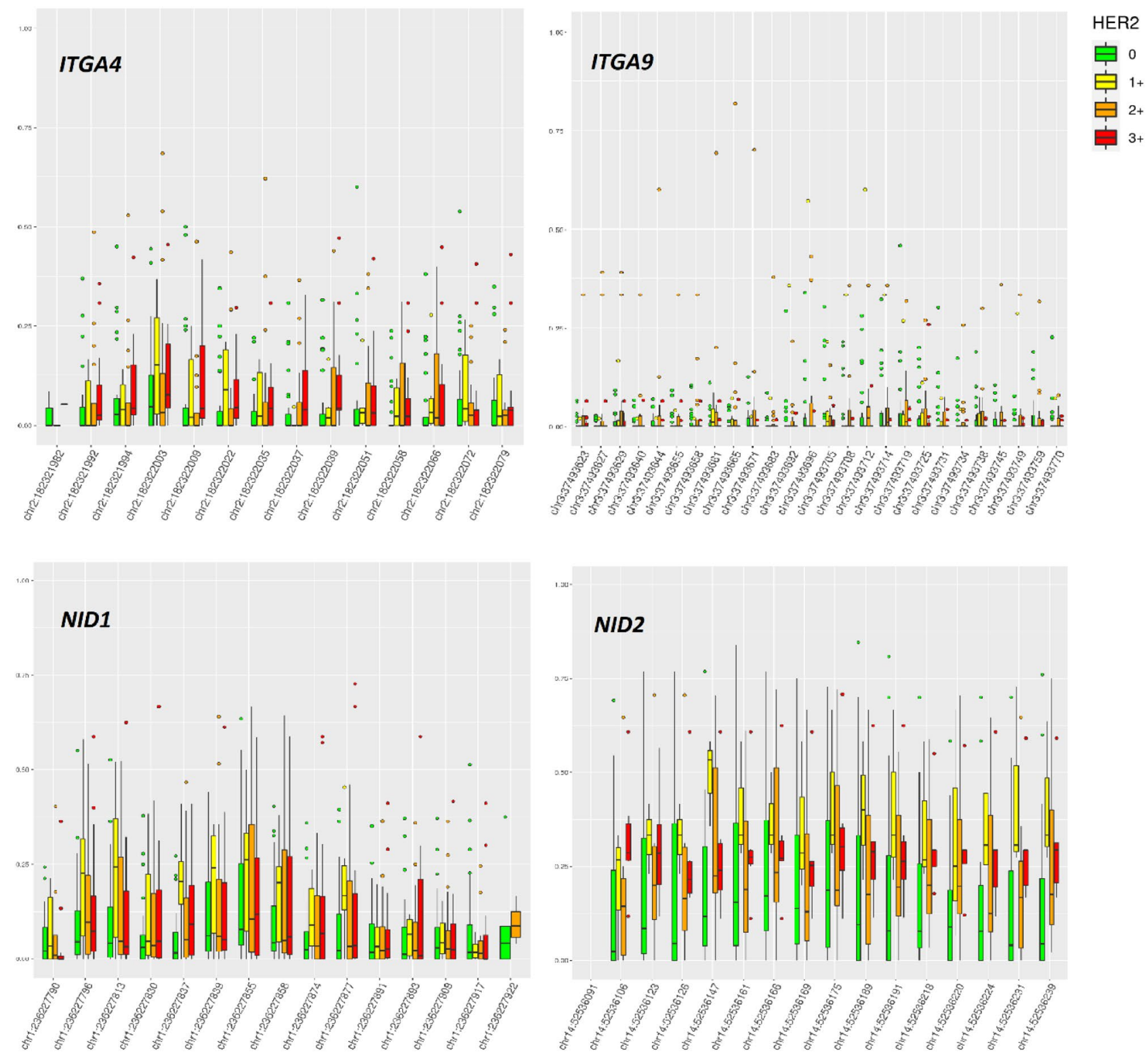

Figure 5. Relative fractions of methylated and nonmethylated alleles, measured in breast cancer samples by XmaI-RRBS, in respect to HER2 expression. Beta values ranging from 0.00 for totally nonmethylated to 1.00 for totally methylated (along the Y-axis) are the estimate of methylation level, and is the fraction of methylated CpG dinucleotides in all CpG dinucleotides assessed in genomic (GRCh37/hg19) positions indicated along the $\mathrm{X}$-axis.

ITGA1 gene promoter was found to be abnormally hypermethylated in 13\% (19/146) samples from our BC tissue collection. ITGA1 is normally expressed in multiple tissues including breast. It was recently shown that ITGA1 is a differentially expressed-aberrantly methylated gene in breast cancer, providing a possible independent functional role of its hypermethylation in $\mathrm{BC}^{35}$. In our study, ITGA1 hypermethylation was not associated with HER2 tumor status, providing further evidence of its independent role in BC tumorigenesis.

The ITGA4 gene promoter showed a high abnormal methylation frequency in our BC tissue collection (48/156 samples, $31 \%$ ). Abnormal hypermethylation of this gene has previously been detected in $41 \%$ of tumor samples and was associated with the HER2 positive immunohistochemistry status and poor differentiation of tumor cells $^{14}$. In the present study we also demonstrate high frequency of abnormal DNA methylation at the ITGA4 gene promoter $\mathrm{CpG}$ island, also associated with the HER2 positive immunohistochemistry status. Do et al. ${ }^{14}$ speculate that such results support a previous study that suggested integrin $\alpha$ and HER2 are involved in the same signaling pathway, referring to the publication describing a novel mechanism for integrin-mediated Ras activation in breast carcinoma cells ${ }^{36}$. Yet, it should be kept in mind that the mentioned mechanism was described for integrin $\alpha 6$, as part of the $\alpha 6 \beta 4$ molecule. Both $\alpha 6$ and $\beta 4$ integrin genes, ITGA6 and ITGB4, are well expressed in the normal mammary tissues, unlike ITGA4, whose expression in normal breast is negligible (the gene expression data were obtained from the GTEx Portal https://www.gtexportal.org on 11/11/20). With this fact alone one 
should be cautious when drawing direct conclusions regarding common mechanisms of action of integrins $\alpha 4$ and $\alpha 6$. Further, the mechanism of integrin a $6 \beta 4$ action implies its involvement in HER2 expression. Depletion of $\beta 4$ by shRNA reduced HER2 protein level without affecting ERBB2 (HER2 gene) mRNA level and reexpression of $\beta 4$ increased HER2 protein level ${ }^{36}$. These results show that integrin $\alpha 6 \beta 4$ positively regulates HER2 through translational control, and we thus should anticipate high $\alpha 6 \beta 4$ in the HER2 positive breast tumors. In the case of ITGA4 in breast cancer, we witness the opposite situation, where the fraction of HER2 positive tumors is significantly enriched with samples harboring ITGA4 methylation. If ITGA4 is silenced by DNA methylation, as it is suggested by the results of several studies ${ }^{11,14,24}$, then integrin $\alpha 4$ should be low in HER2 positive tumors. Indeed, the question to discuss in the context of ITGA4 abnormal hypermethylation in $\mathrm{BC}$, is what the reason may be for the gene negligibly expressed in the normal tissue to become hypermethylated in the tumor of the same organ. We have recently suggested based on the examples of other extracellular matrix related molecules ${ }^{37}$, that cancer-specific abnormal hypermethylation of the genes that are not expressed in the same normal tissue might be a "passenger" epigenetic event reflecting merely a CIMP (CpG island methylator phenotype) of a tumor. Yet, while this may be an explanation for other genes found abnormally hypermethylated in BC samples in our study, as far as their hypermethylation well correlates with the CIMP phenotype (Table 3), this is not the case for ITGA4 which is significantly more frequently found in tumors with moderate genome-wide levels of CpG islands methylation. Still, ITGA4 hypermethylation is strongly associated with HER2 hyperexpression, and the association is more pronounced than for the other genes (Table 2). In terms of tumor evolution, this finding might reflect advantage for the cells in which elevation of ITGA4 expression was occasionally "preventively prohibited" by its promoter methylation. Like any other $\mathrm{CpG}$ island, that of the ITGA4 gene may acquire abnormal methylation in the process of cancer progression given general deregulation of epigenetic processes in tumors. If under any circumstances the mechanisms of ITGA4 transcription in a tumor are activated (the activating mechanisms may be, for example, ectopic expression of a transcription factor, or activation of an otherwise inactive topologically associating domain), it would be more effective in the cells with nonmethylated ITGA4 promoter then in those with the hypermethylated one. Then cells with nonmethylated ITGA4 alleles would produce integrin $\alpha 4$ protein the function of which in cancer is not yet well understood but, judging by depletion of nonmethylated ITGA4 alleles from the HER2 positive tumors, simultaneous presence of both HER2 and integrin $\alpha 4$ receptors is not beneficial for tumor cells (Fig. 6). This may suggest importance of HER2 and integrin a 4 signaling pathways interactions that are yet to be discovered. Important though is the fact that in the HER2 positive tumors we never find hypermethylation of more than $50 \%$ of ITGA4 alleles (Figs. 5, 7) and BC samples with completely nonmethylated ITGA4 also exist, which suggests that simultaneous expression of HER2 and integrin $\alpha 4$ is not lethal, but rather renders some evolutionary disadvantage for the tumor cells that acquire such expression pattern.

ITGA7 promoter CpG island was abnormally hypermethylated in $4 \%(6 / 156)$ samples in our study. Although The Cancer Genome Atlas data assessed by TCGA Wanderer ${ }^{38}$ indicate that ITGA7 methylation at the region that we assessed tend to downregulate its expression, the number of hypermethylated samples is too small in our collection to draw any conclusions on the associations with clinical and molecular characteristics of the tumors.

In the present study, the ITGA9 gene showed a high (39\%) frequency of abnormal methylation in our collection of BC samples. This supports a previous report where in breast tumors, ITGA9 expression was downregulated or totally absent in $44 \%$ of cases and intact or upregulated in $45 \%$ of cases, and the frequency of ITGA9 promoter methylation was $90 \%$ in the former group; while treatment with the demethylating agent 5-aza-dC restored integrin a9 expression in ITGA9-negative cells of the MCF7 line ${ }^{18}$.

\section{Conclusions}

In this study, we have identified high frequencies of cancer specific abnormal hypermethylation of the parts of promoter regions of integrin ITGA1, ITGA4, ITGA9, and nidogen NID1, NID2 genes in breast cancer. Although their abnormal hypermethylation is cancer specific and frequent in breast tumors, which makes them attractive candidates for diagnostic markers, in the plain of tumor biology we suggest that this hypermethylation might be mere a "passenger" epigenetic event reflecting tumor CpG island methylator phenotype (CIMP). For the only gene among listed, ITGA4, abnormal hypermethylation is not correlated with CIMP, but is strongly correlated with high levels of HER2 expression in breast tumors. This finding may suggest importance of HER2 and integrin a4 signaling pathways interactions that are yet to be discovered. Data on possible involvement of receptors known to be overexpressed in breast cancer in regulation of integrin genes expression are gradually accumulating. It has very recently been suggested that estrogen receptor $\alpha$ is involved in the regulation of ITGA 8 methylation in estrogen receptor-positive breast cancer ${ }^{39}$. Further elaboration of this subject promises new exciting insights in cancer epigenomics.

\section{Materials and methods}

Clinical material. We examined 156 BC samples, 156 matched samples of morphologically normal adjacent tissue, five BC cell lines (ZR711, HS578T, BT474, T47D, and MCF7), and six autopsy samples of normal breast tissues. Biological material was obtained from the Blokhin Russian Cancer Research Center, Gertsen Moscow Research Cancer Institute, Research Centre for Medical Genetics, Institute of Gene Biology, and Russian Scientific Center of Roentgenoradiology. Altogether, 323 samples have been analyzed in this study. All BC and matched samples were obtained at surgery of cancer cases none of which underwent neoadjuvant chemotherapy. All tissue samples were fresh-frozen. Fragments of tissues for DNA analysis were examined macro- and micromorphologically: expression of ER, PR, and HER2 receptors was evaluated by immunohistochemistry. Negative HER2 status was diagnosed in 72 samples (46\%); HER2 "1+", " $2+$ " and " $3+$ " positivity was documented for 34 (22\%), $31(20 \%)$, and $19(12 \%)$ samples, respectively. 


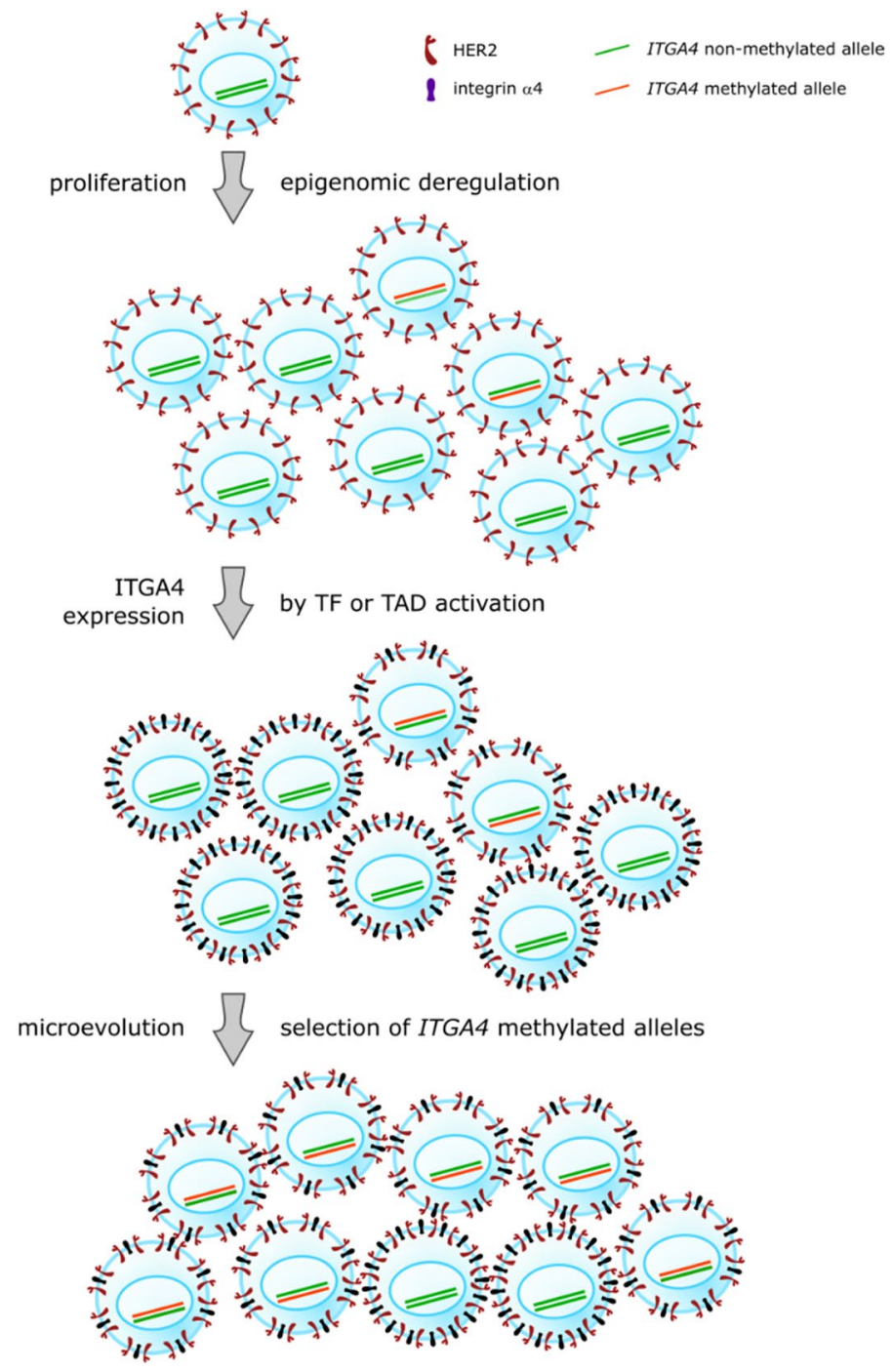

Figure 6. A hypothetical mechanism for the tumor microevolution advantage of the methylated ITGA4 gene promoter in HER2 positive breast tumors. The hypothesis is that co-expression of the HER2 and integrin $a 4$ receptors might reduce microevolution fitness of cancer cells; "preventive prohibition" of the ITGA4 gene expression by its promoter methylation provides advantage for the cells in cases when under any circumstances the mechanisms of ITGA4 transcription in a tumor are activated (see detailed explanation in the text). TF, transcription factor; TAD, topologically associating domain.

The approximate amount of tumor cells in each sample was estimated to exceed $80 \%$. Fragments of about $10 \mathrm{mg}$ were used for DNA extraction.

This study was conducted in accordance with the Declaration of Helsinki, and was approved by the Bioethics Committee of Research Centre for Medical Genetics. Written informed consent was obtained from each participant of this study.

Of the 156 BC samples, 79\% (123/156) were identified as ductal BC; 8\% (13/156), as lobular BC; and 6\% (9/156), as mixed BC. Micropapillary carcinoma and mucinous, medullary, metaplastic, and low-differentiated $\mathrm{BC}$ were diagnosed in single cases.

The disease stage at diagnosis was identified as I in $12 \%$ (19/156), IIA in $40 \%(63 / 156)$, IIB in $33 \%(51 / 156)$, IIIA in $6 \%(10 / 156)$, and IIIB in 6\% (9/156), IIIC in $1 \%(2 / 156)$, and IV in $1 \%(2 / 156)$ of the patients.

DNA isolation and methylation-sensitive restriction enzyme digestion. Genomic DNA was isolated by standard phenol-chloroform extraction. The DNA digestion mixture for the methylation-sensitive restriction enzyme digestion contained $1.5 \mu \mathrm{g}$ of genomic DNA, 10 units of HpaII restriction endonuclease, and $2 \mu \mathrm{L}$ of a SEBufferY buffer (10x) (SibEnzyme, Russia). Deionized water was added to bring the final volume to $20 \mu \mathrm{L}$, and the mixture was incubated at $37^{\circ} \mathrm{C}$ for $16 \mathrm{~h}$. 


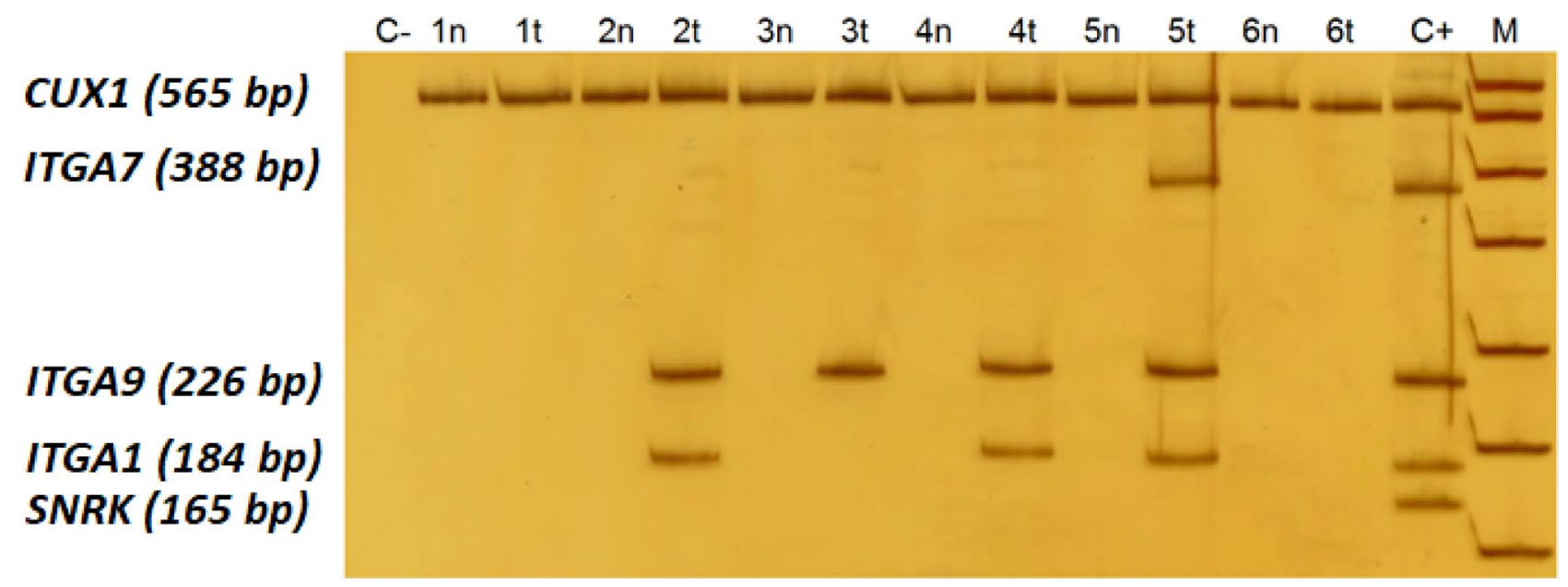

Figure 7. Simultaneous analysis of the fragments of the ITGA1, ITGA7 and ITGA9 genes promoters by MSRE-PCR. C-, negative MSRE-PCR control; 1-6, MSRE-PCR products obtained with breast cancer genomic DNA samples digested with HpaII, where " $n$ " stands for the apparently normal morphologically intact tissue samples, and " $\mathrm{t}$ " stands for the matching tumor tissue samples; C+, MSRE-PCR products obtained with an undigested human genomic DNA as a template (positive sample control); M, DNA ladder pUC19/HpaII. Positions of the PCR products corresponding to the ITGA1, ITGA7 and ITGA9 promoter CpG islands under analysis, as well as a to a positive PCR control (a constitutively methylated region of the CUX1 gene), and to a DNA digestion control (a constitutively nonmethylated region of the SNRK gene) are specified on the left. Samples 1 and 6 demonstrate nonmethylated status at the CpG islands of all the three target genes in both tumor and adjacent tissues; sample 2 shows methylated ITGAI and ITGA9 and nonmethylated ITGA7 in tumor tissue; sample 3 demonstrates methylation of ITGA9 in tumor; sample 4 demonstrates methylation of ITGA 1 and ITGA9 in tumor tissue; sample 5 shows methylation of all the three target genes in tumor sample. MSRE-PCR does not provide information on the methylation status of individual CpGs contained within the restriction enzyme recognition sequence in an assessed locus. Thus, positive MSRE-PCR signal was interpreted as hypermethylation of the whole target locus, while negative MSRE-PCR signal, as its nonmethylated state. The original full-length gel used for this Figure is shown on Supplementary Fig. S1.

Methylation-sensitive restriction enzyme digestion PCR (MSRE-PCR) assays. Triplex MSREPCR assays were used for each locus under study, where one fragment was amplified from the target gene, another one served as a positive PCR control (a constitutively methylated region of the CUX1 gene ${ }^{5}$ ), and a third one was used to check the completeness of DNA hydrolysis (a constitutively nonmethylated region of $S N R K^{5}$ ). Target loci with distinctly different amplicon lengths may be combined in the single-tube multiplex reactions (Fig. 5). The nucleotide sequences of the primers are shown in Table 4. PCR reactions were performed as described earlier ${ }^{5}$. The MSRE-PCR products were resolved by electrophoresis in $8 \%$ polyacrylamide gel and stained with silver nitrate (Fig. 7).

Bisulfite sequencing by sanger. The results of the analysis of promoter methylation of target genes obtained by MSRE-PCR were verified with bisulfite sequencing of corresponding fragments. For bisulfite conversion, genomic DNA was denatured in $\mathrm{NaOH}$ (at a final concentration of $0.3 \mathrm{M}$ ) at $65^{\circ} \mathrm{C}$ for $15 \mathrm{~min}$. DNA was modified using sodium bisulfite and hydroquinone taken at final concentrations $2 \mathrm{M}$ and $0.5 \mathrm{M}$, respectively, for $15 \mathrm{~h}$ at $55^{\circ} \mathrm{C}$. Modified DNA was purified using Wizard DNA Cleanup system (Promega, USA) according to the manufacturer's instructions. PCR reactions were performed as described earlier ${ }^{5}$. PCR products were sequenced with an ABI3100 genetic analyzer using terminating dideoxynucleotides according to the protocol for ABI Prism 3100 Genetic Analyzer (Thermo Fisher Scientific, Waltham, Massachusetts, USA). The nucleotide sequences of the primers are shown in Table 5.

Validation of MSRE-PCR results by RRBS. For the validation of MSRE-PCR results by RRBS, two RRBS datasets were used, one from the ENCODE project ${ }^{33}$, and another from our previous XmaI-RRBS study ${ }^{34}$ performed on a subset of $64 \mathrm{BC}$ samples, five BC cell lines and six normal breast samples matching the samples from the collection described here. XmaI-RRBS was performed as described by us earlier ${ }^{40}$. A representative example of XmaI-RRBS results visualized with Integrative Genomic Viewer ${ }^{41}$ (IGV) is shown on Fig. 8. 


\begin{tabular}{|c|c|c|c|c|}
\hline Gene & Primers & $\begin{array}{l}\text { Amplicon co-ordinates, GRCh37/hg19 } \\
\text { [distance to transcription start site (TSS)] }\end{array}$ & PCR product size, bp & $\begin{array}{l}\text { Number of HpaII sites within MSRE-PCR } \\
\text { fragment }\end{array}$ \\
\hline ITGAl & $\begin{array}{l}\text { F: ATAAGTGGCCCAGCCAGAG } \\
\text { R: GCAGGAGATGCTCAGAGAAAA }\end{array}$ & $\begin{array}{l}\text { chr5:52,084,099-52,084,282 } \\
\text { (includes TSS) }\end{array}$ & 184 & 2 \\
\hline ITGA2 & $\begin{array}{l}\text { F: CCCCTAGGCACTGTGGTTTA } \\
\text { R: AGGCTTTCCTGCCCTGGAC }\end{array}$ & $\begin{array}{l}\text { chr5:52,284,728-52,284,933 } \\
\text { (222 upstream) }\end{array}$ & 206 & 2 \\
\hline ITGA3 & $\begin{array}{l}\text { F: AGCAGGTGAACAGGTCCTCA } \\
\text { R: TACCAGGAATCGGGTATCCA }\end{array}$ & $\begin{array}{l}\text { chr17:48,133,728-48,133,926 } \\
\text { (388 bp downstream) }\end{array}$ & 199 & 3 \\
\hline ITGA4 & $\begin{array}{l}\text { F: CCCCATCAGGTCCGCTCTTG } \\
\text { R: CCCCACTCCCGGTTTCTGCC }\end{array}$ & $\begin{array}{l}\text { chr2:182,321,921-182,322,166 } \\
\text { (301 bp downstream) }\end{array}$ & 246 & 6 \\
\hline ITGA6 & $\begin{array}{l}\text { F: CGAAGGTGGCTGCGGTAG } \\
\text { R: CAGCGAGAAGCCGAAGAG }\end{array}$ & $\begin{array}{l}\text { chr2:173,292,417-173,292,660 (103 bp down- } \\
\text { stream) }\end{array}$ & 244 & 5 \\
\hline ITGA7 & $\begin{array}{l}\text { F: AATGAGGAGGCCCACAGAG } \\
\text { R: CCAACGAGACTTTGGAGACC }\end{array}$ & $\begin{array}{l}\text { chr12:56,101,182-56,101,569 } \\
\text { (117 bp downstream) }\end{array}$ & 388 & 3 \\
\hline ITGA9 & $\begin{array}{l}\text { F: GTTCTTCGGCTACGCAGTTC } \\
\text { R: ACGGCGTCCTCCCTTCTC }\end{array}$ & $\begin{array}{l}\text { chr3:37,494,003-37,494,228 } \\
\text { (190 bp downstream) }\end{array}$ & 226 & 3 \\
\hline ITGB1 & $\begin{array}{l}\text { F: GGGTCTGAGCACAAGCTG } \\
\text { R: CAGTCCACTTCCCCGTGTT }\end{array}$ & $\begin{array}{l}\text { chr10:33,246,321-33,246,420 } \\
\text { (402 bp downstream) }\end{array}$ & 100 & 3 \\
\hline NID1 & $\begin{array}{l}\text { F: GTCCTCCAGCTCCAGGTCCC } \\
\text { R: CATCCCCGCCTTCCTCTGTC }\end{array}$ & $\begin{array}{l}\text { chr1:236,228,236-236,228,440 } \\
\text { (41 bp downstream) }\end{array}$ & 205 & 4 \\
\hline NID2 & $\begin{array}{l}\text { F:GGAAGAGCTCGTCTGGGTGCAG } \\
\text { R: CGCGGAGATCCAGGTTCGAG }\end{array}$ & $\begin{array}{l}\text { chr14:52,535,601-52,535,810 } \\
\text { (136 bp downstream) }\end{array}$ & 210 & 4 \\
\hline$D A G 1$ & $\begin{array}{l}\text { F: GCTGGATTGGCTGCAACACT } \\
\text { R: GCAGGTGTTCGCTCCTCCTG }\end{array}$ & $\begin{array}{l}\text { chr3:49,507,618-49,507,843 } \\
\text { (53 bp downstream) }\end{array}$ & 226 & 3 \\
\hline CUX1 & $\begin{array}{l}\text { F: GCCCCCGAGGACGCCGCTACC } \\
\text { R: AGGCGGTCCAGGGGTCCAGGC }\end{array}$ & $\begin{array}{l}\text { chr7:101,892,050-101,892,614 } \\
\text { 3'-UTR }\end{array}$ & 565 & 6 \\
\hline SNRK & $\begin{array}{l}\text { F: GCTGGGTGCGGGGTTTCGGCG } \\
\text { R: CGGAGGCTACTGAGGCGGCGG }\end{array}$ & $\begin{array}{l}\text { chr3:43,328,087-43,328,251 } \\
\text { (84 bp downstream) }\end{array}$ & 165 & 3 \\
\hline
\end{tabular}

Table 4. Primers used to assess the methylation status of the integrin, nidogen, and dystroglycan genes by methylation-sensitive restriction enzyme digestion PCR.

\begin{tabular}{|l|l|l|l|}
\hline Gene & Primers & $\begin{array}{l}\text { Amplicon co-ordinates, GRCh37/hg19 [distance to } \\
\text { transcription start site (TSS)] }\end{array}$ & PCR product size, bp \\
\hline ITGA7 & $\begin{array}{l}\text { F: AGTAGGGAGTTAAAAAGGTAGTAAAT } \\
\text { R: CCTAAAAAAACCTAAAACTTAAAA }\end{array}$ & chr12:56,101,399-56,101,540 (103 bp downstream) & 142 \\
\hline NID2 & $\begin{array}{l}\text { F: GTGGGGTTTTTTGGGGGT } \\
\text { R: CAATAACCACCACATCTAATTCTC }\end{array}$ & chr14:52,535,906-52,536,087 (includes TSS) & 182 \\
\hline
\end{tabular}

Table 5. Primers used to assess methylation of the ITGA7 and NID2 promoter regions by bisulfite Sanger sequencing.

Statistical analysis. Statistical significance of associations between the methylated gene status and high HER2 expression was assessed by the $\chi^{2}$ and Fisher's exact tests. Associations between the methylated gene status and genome-wide tumor methylotype were assessed by the Fisher's exact test. Multiple correspondence analysis (Fig. 1) was carried out with Multiple Correspondence Analysis (MCA) software STATISTICA Version10. Distribution of methylation beta values in respect to HER2 expression in tumor samples was illustrated (Fig. 3) using ggplot2 package for R language. Influence of the methylation status of exact CpG dinucleotides on gene expression in BC was assessed using The Cancer Genome Atlas (TCGA) datasets using TCGA Wanderer ${ }^{38}$ at http://maplab.imppc.org/wanderer. 

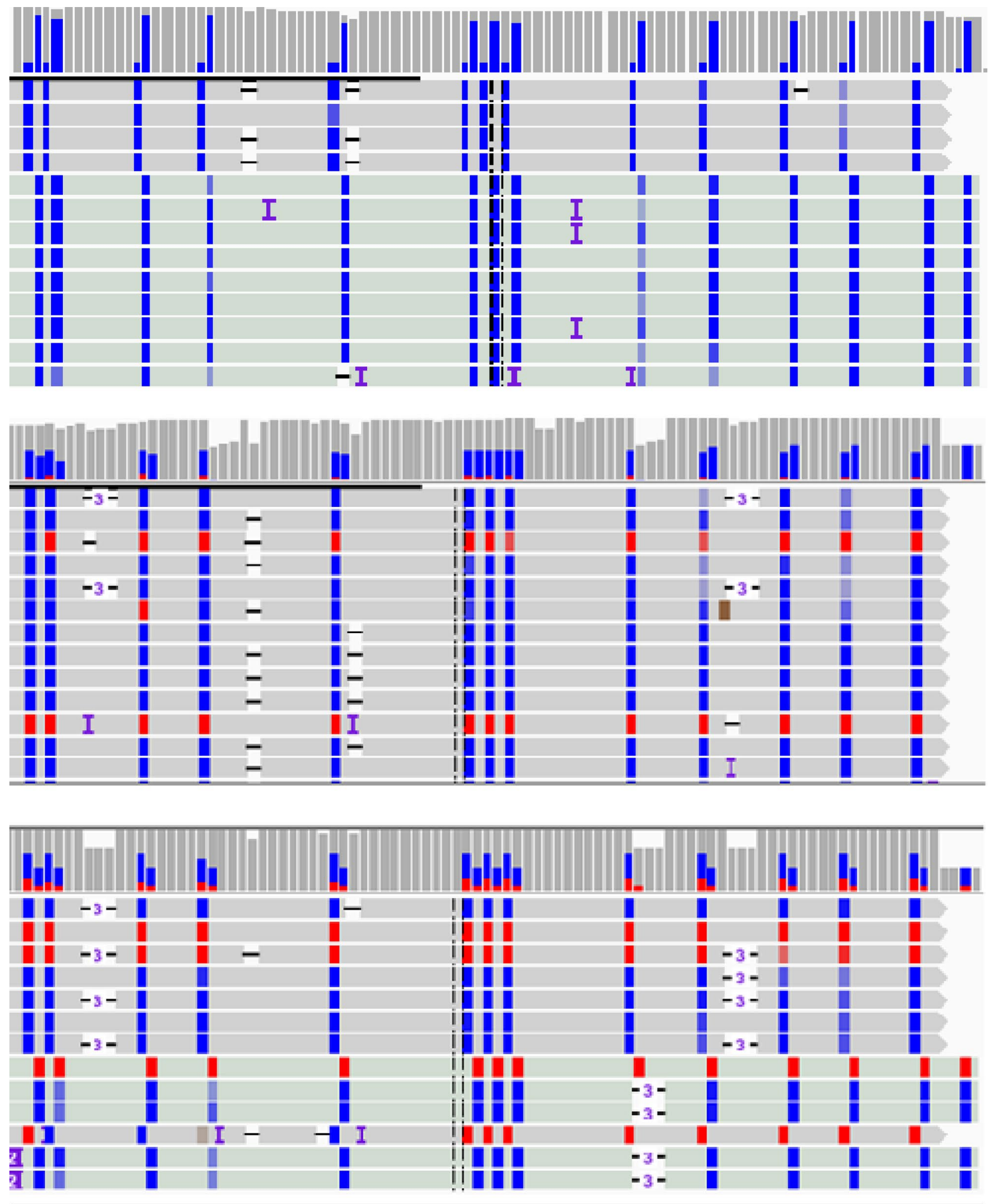

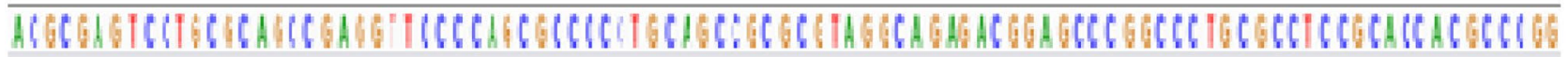

Figure 8. Methylation of a fragment of the ITGA4 gene promoter assessed by reduced representation bisulfite sequencing (XmaI-RRBS). Each track represents a sequence (read) of a single molecule from the sample. A fragment of 96 base pairs is presented, sequenced in a normal breast tissue sample (upper panel) and in two different HER2 positive breast cancer samples (two lower panels). Red is for methylated cytosines and blue is for nonmethylated cytosines in the CpG context. Reference genome sequence is at the bottom. Symbols "-" and "-3-" seen within the reads reflect spurious single nucleotide and trinucleotide deletions, correspondingly, that arise as technical errors in detecting the lengths of homopolynucleotide tracts (poly-T and poly-A) arising as a result of bisulfite DNA conversion. 
Received: 21 August 2020; Accepted: 12 January 2021

Published online: 26 January 2021

\section{References}

1. Egeblad, M., Nakasone, E. S. \& Werb, Z. Tumors as organs: Complex tissues that interface with the entire organism. Dev. Cell. 18, 884-901. https://doi.org/10.1016/j.devcel.2010.05.012 (2010).

2. Covaceuszach, S. et al. Structural flexibility of human $\alpha$-dystroglycan. FEBS Open Bio. 7, 1064-1077. https://doi.org/10.1002/22115463.12259 (2017)

3. Pan, L., Zhao, Y., Yuan, Z. \& Qin, G. Research advances on structure and biological functions of integrins. Springerplus. 5, 1094. https://doi.org/10.1186/s40064-016-2502-0 (2016).

4. Moreno-Layseca, P. et al. The requirement of integrins for breast epithelial proliferation. Eur. J. Cell. Biol. 96, 227-239. https://doi. org/10.1016/j.ejcb.2017.03.005 (2017).

5. Simonova, O. A. et al. DNA methylation in the promoter regions of the laminin family genes in normal and breast carcinoma tissues. Mol. Biol. 49, 598-607. https://doi.org/10.1134/S0026893315040160 (2015).

6. Durbeej, M. Laminins. Cell Tissue Res. 339, 259-268. https://doi.org/10.1007/s00441-009-0838-2 (2010).

7. Yamada, M. \& Sekiguchi, K. Molecular basis of Laminin-Integrin interactions. Curr. Top. Membr. 76, 197-229. https://doi. org/10.1016/bs.ctm.2015.07.002 (2015).

8. Lössl, P. et al. Analysis of nidogen-1/laminin $\gamma 1$ interaction by cross-linking, mass spectrometry, and computational modeling reveals multiple binding modes. PLoS ONE 9, e112886. https://doi.org/10.1371/journal.pone.0112886 (2014).

9. Yurchenco, P. D. \& Patton, B. L. Developmental and pathogenic mechanisms of basement membrane assembly. Curr. Pharm. Des. 15, 1277-1294. https://doi.org/10.2174/138161209787846766 (2009).

10. Patrick, C. W. Jr. \& Wu, X. Integrin-mediated preadipocyte adhesion and migration on laminin-1. Ann. Biomed. Eng. 31, 505-514. https://doi.org/10.1114/1.1566446 (2003).

11. Park, J. et al. Aberrant methylation of integrin $\alpha 4$ gene in human gastric cancer cells. Oncogene 23, 3474-3480. https://doi. org/10.1038/sj.onc.1207470 (2004)

12. Mostafavi-Pour, Z. et al. Methylation of integrin $a 4$ and E-cadherin genes in human prostate cancer. Pathol. Oncol. Res. 21, 921-927. https://doi.org/10.1007/s12253-015-9917-8 (2015).

13. Uhm, K. O. et al. Aberrant DNA methylation of integrin a4: A potential novel role for metastasis of cholangiocarcinoma. J. Cancer Res. Clin. Oncol. 136, 187-194. https://doi.org/10.1007/s00432-009-0646-9 (2010).

14. Do, S. I. et al. Aberrant DNA methylation of integrin $\alpha 4$ in human breast cancer. Tumor Biol. 35, 7079-7084. https://doi.org/10.1007/ s13277-014-1952-7 (2014).

15. Kon, S. \& Uede, T. The role of $\alpha 9 \beta 1$ integrin and its ligands in the development of autoimmune diseases. J. Cell Commun. Signal. 12, 333-342. https://doi.org/10.1007/s12079-017-0413-7 (2018).

16. Fiorilli, P. et al. Integrins mediate adhesion of medulloblastoma cells to tenascin and activate pathways associated with survival and proliferation. Lab. Investig. 88, 1143-1156. https://doi.org/10.1038/labinvest.2008.89 (2008).

17. Brown, M. C. et al. Regulatory effect of nerve growth factor in $\alpha 9 \beta 1$ integrin-dependent progression of glioblastoma. Neuro Oncol. 10, 968-980. https://doi.org/10.1215/15228517-2008-047 (2008).

18. Mostovich, L. A. et al. Integrin alpha9 (ITGA9) expression and epigenetic silencing in human breast tumors. Cell Adhes. Migr. 5, 395-401. https://doi.org/10.4161/cam.5.5.17949 (2011).

19. Mitra, S. et al. RBSP3 is frequently altered in premalignant cervical lesions: Clinical and prognostic significance. Genes Chromosomes Cancer. 49, 155-170. https://doi.org/10.1002/gcc.20726 (2010).

20. Meyer, C. et al. An interstitial deletion at 3p21.3 results in the genetic fusion of MLH1 and ITGA9 in a Lynch syndrome family. Clin. Cancer Res. 15, 762-769. https://doi.org/10.1158/1078-0432.CCR-08-1908 (2009).

21. Hitchins, M. P. et al. Epigenetic inactivation of a cluster of genes flanking MLH1 in microsatellite-unstable colorectal cancer. Cancer Res. 67, 9107-9116. https://doi.org/10.1158/0008-5472.CAN-07-0869 (2007).

22. Deb, M., Sengupta, D. \& Patra, S. K. Integrin-epigenetics: A system with imperative impact on cancer. Cancer Metastasis Rev. 31, 221-234. https://doi.org/10.1007/s10555-011-9341-9 (2012).

23. Wu, J. et al. Characterization of DNA methylation associated gene regulatory networks during stomach cancer progression. Front. Genet. 9, 711. https://doi.org/10.3389/fgene.2018.00711 (2019).

24. Chang, E. et al. Detection of colorectal neoplasm using promoter methylation of ITGA4, SFRP2, and p16 in stool samples: A preliminary report in Korean patients. Hepatogastroenterology. 57, 720-727 (2010).

25. Klemke, M., Weschenfelder, T., Konstandin, M. H. \& Samstag, Y. High affinity interaction of integrin $\alpha 4 \beta 1$ (VLA-4) and vascular cell adhesion molecule 1 (VCAM-1) enhances migration of human melanoma cells across activated endothelial cell layers. J. Cell. Physiol. 212, 368-374. https://doi.org/10.1002/jcp.21029 (2007).

26. Weir, M. L. et al. Dystroglycan loss disrupts polarity and $\beta$-casein induction in mammary epithelial cells by perturbing laminin anchoring. J. Cell Sci. 119, 4047-4058. https://doi.org/10.1242/jcs.03103 (2006).

27. Muschler, J. et al. A role for dystroglycan in epithelial polarization: Loss of function in breast tumor cells. Cancer Res. 62, 7102-7109 (2002).

28. Pujuguet, P. et al. Nidogen-1 regulates laminin-1-dependent mammary-specific gene expression. J. Cell Sci. 113, 849-858 (2000).

29. Mokkapati, S., Bechtel, M., Reibetanz, M., Miosge, N. \& Nischt, R. Absence of the basement membrane component nidogen 2, but not of nidogen 1, results in increased lung metastasis in mice. J. Histochem. Cytochem. 60, 280-289. https://doi.org/10.1369/00221 $55412436586(2012)$

30. Herzog, C., Marisiddaiah, R., Haun, R. S. \& Kaushal, G. P. Basement membrane protein nidogen- 1 is a target of meprin $\beta$ in cisplatin nephrotoxicity. Toxicol. Lett. 236, 110-116. https://doi.org/10.1016/j.toxlet.2015.05.005 (2015).

31. Ulazzi, L. et al. Nidogen 1 and 2 gene promoters are aberrantly methylated in human gastrointestinal cancer. Mol. Cancer. 6, 17. https://doi.org/10.1186/1476-4598-6-17 (2007).

32. Ferraro, D. A. et al. Endothelial cell-derived nidogen-1 inhibits migration of SK-BR-3 breast cancer cells. BMC Cancer. 19, 312. https://doi.org/10.1186/s12885-019-5521-8 (2019).

33. Wang, H. et al. Widespread plasticity in CTCF occupancy linked to DNA methylation. Genome Res. 22, 1680-1688. https://doi. org/10.1101/gr.136101.111 (2012).

34. Tanas, A. S. et al. Genome-wide methylotyping resolves breast cancer epigenetic heterogeneity and suggests novel therapeutic perspectives. Epigenomics. 11, 605-617. https://doi.org/10.2217/epi-2018-0213 (2019).

35. Qi, L. et al. Significant prognostic values of differentially expressed-aberrantly methylated hub genes in breast cancer. J. Cancer. 10, 6618. https://doi.org/10.7150/jca.33433 (2019).

36. Yoon, S. O., Shin, S. \& Lipscomb, E. A. A novel mechanism for integrin-mediated ras activation in breast carcinoma cells: The a6 34 integrin regulates ErbB2 translation and transactivates epidermal growth factor receptor/ErbB2 signaling. Cancer Res. 66, 2732-2739. https://doi.org/10.1158/0008-5472.CAN-05-2941 (2006).

37. Simonova, O. A. et al. Abnormal hypermethylation of $\mathrm{CpG}$ dinucleotides in promoter regions of matrix metalloproteinases genes in breast cancer and its relation to epigenomic Subtypes and HER2 overexpression. Biomedicines. 8, 116. https://doi.org/10.3390/ biomedicines8050116 (2020) 
38. Díez-Villanueva, A., Mallona, I. \& Peinado, M. A. Wanderer, an interactive viewer to explore DNA methylation and gene expression data in human cancer. Epigenet. Chromatin. 8, 22. https://doi.org/10.1186/s13072-015-0014-8 (2015).

39. Wu, J. et al. Estrogen receptor $\alpha$ is involved in the regulation of ITGA8 methylation in estrogen receptor-positive breast cancer. Ann. Transl. Med. 8, 993. https://doi.org/10.21037/atm-20-5220 (2020).

40. Tanas, A. S. et al. Rapid and affordable genome-wide bisulfite DNA sequencing by XmaI-reduced representation bisulfite sequencing. Epigenomics. 9, 833-847. https://doi.org/10.2217/epi-2017-0031 (2017).

41. Robinson, J. T. et al. Integrative genomics viewer. Nat. Biotechnol. 29, 24-26. https://doi.org/10.1038/nbt.1754 (2011).

\section{Acknowledgements}

The research was supported by Russian Science Foundation (project № 18-15-00430).

\section{Author contributions}

Conceptualization, V.V.S. and O.A.S.; Data curation, M.V.N. and O.A.S.; Funding acquisition, V.V.S. and S.I.K.; Investigation, O.A.S. and A.I.K; Methodology, E. B. K., A.S.T., D.V.Z. and M.V.N.; Resources, E.V.P, T.V.K., I.D.T. and S.S.L.; Software, V.V.R.; Drawing, V.V.S. and A.S.T.; Supervision, S.I.K.; Writing-original draft, V.V.S. and O.A.S.; Writing-review \& editing, A.S.T, D.V.Z. and G.G.C. All authors read, reviewed and approved the final manuscript.

\section{Competing interests}

The authors declare no conflict of interest. The funders had no role in the design of the study; in the collection, analyses, or interpretation of data; in the writing of the manuscript, or in the decision to publish the results.

\section{Additional information}

Supplementary Information The online version contains supplementary material available at https://doi. org/10.1038/s41598-021-81851-y.

Correspondence and requests for materials should be addressed to V.V.S.

Reprints and permissions information is available at www.nature.com/reprints.

Publisher's note Springer Nature remains neutral with regard to jurisdictional claims in published maps and institutional affiliations.

Open Access This article is licensed under a Creative Commons Attribution 4.0 International License, which permits use, sharing, adaptation, distribution and reproduction in any medium or format, as long as you give appropriate credit to the original author(s) and the source, provide a link to the Creative Commons licence, and indicate if changes were made. The images or other third party material in this article are included in the article's Creative Commons licence, unless indicated otherwise in a credit line to the material. If material is not included in the article's Creative Commons licence and your intended use is not permitted by statutory regulation or exceeds the permitted use, you will need to obtain permission directly from the copyright holder. To view a copy of this licence, visit http://creativecommons.org/licenses/by/4.0/.

(C) The Author(s) 2021 